\title{
Contralateral psoas hematoma after minimally invasive, lateral retroperitoneal transpsoas lumbar interbody fusion: a multicenter review of $\mathbf{3 9 5 0}$ lumbar levels
}

\author{
Joshua M. Beckman, MD, ${ }^{1}$ Berney Vincent, BA, ${ }^{1}$ Michael S. Park, MD, ${ }^{1}$ James B. Billys, MD, ${ }^{2}$ \\ Robert E. Isaacs, MD, ${ }^{3}$ Luiz Pimenta, MD, PhD, ${ }^{4}$ and Juan S. Uribe, MD ${ }^{1}$ \\ ${ }^{1}$ Department of Neurosurgery \& Brain Repair, Morsani College of Medicine, University of South Florida, Tampa; ${ }^{2}$ Center for \\ Spinal Disorders, Florida Orthopaedic Institute, Tampa, Florida; ${ }^{3}$ Division of Neurosurgery, Department of Surgery, Duke \\ University Medical Center, Durham, North Carolina; and ${ }^{4}$ Instituto de Patologia da Coluna, São Paulo, Brazil
}

\begin{abstract}
OBJECTIVE Minimally invasive lateral lumbar interbody fusion (LLIF) via the retroperitoneal transpsoas approach is a technically demanding procedure with a multitude of potential complications. A relatively unknown complication is the contralateral psoas hematoma. The authors speculate that injury occurs from segmental vessel injury at the time of contralateral annulus release; however, this is not fully understood. In this multicenter retrospective review, the authors report the incidence of this contralateral complication and its neurological sequelae.
\end{abstract}

METHODS This study was a retrospective chart review of all minimally invasive LLIF performed at participating institutions from 2008 to 2014. Exclusion criteria included an underlying diagnosis of trauma or neoplasia as well as lateral corpectomies or anterior column releases. Single-level, multilevel, and stand-alone constructs were included. All patients underwent preoperative MRI. Follow-up was at least 12 months. All complications and clinical outcomes were selfreported by each surgeon.

RESULTS There were 3950 lumbar interbody cages placed via the retroperitoneal transpsoas approach, with 7 cases ( $0.18 \%$ incidence) of symptomatic contralateral psoas hematoma, 3 of which required reoperation for hematoma evacuation. Neurological outcome did not improve after reoperation. Reoperation occurred an average of 1 month after the initial operation due to a delay in diagnosis. In 1 case, segmental artery injury was confirmed at the time of surgery; in the others, segmental vessel injury was suspected, although it could not be confirmed. Neurological deficits persisted in 3 patients while the others remained neurologically intact. Two patients were receiving antiplatelet therapy prior to the procedure.

CONCLUSIONS The contralateral psoas hematoma is a rare complication suspected to occur from segmental vessel injury during contralateral annulus release. Detailed review of preoperative imaging for aberrant vessel anatomy may prevent injury and subsequent neurological deficit.

http://thejns.org/doi/abs/10.3171/2016.4.SPINE151040

KEY WORDS lateral lumbar interbody fusion; psoas hematoma; segmental vessel; transpsoas; complication

$\mathrm{R}$ ETROPERITONEAL transpsoas lateral lumbar interbody fusion (LLIF) is an increasingly popular but technically demanding procedure. Although it is considered minimally invasive by many, this does not underscore the increased risk profile that is accompanied by a procedure highly dependent on positioning, electromyographic stimulation, and fluoroscopic guidance rather than direct visual conformation of anatomical structures. Despite meticulous surgical technique and detailed preoperative planning, complications are still reported. For surgeons to improve outcomes and minimize these risks, we must remain transparent about our complications and learn from our own experiences and those of our colleagues.

Complications from LLIF have been well documented in the literature. ${ }^{1-6,10,12-14}$ An uncommon or potentially underreported complication is the psoas hematoma on the 
contralateral side of lateral access. In this multicenter retrospective series, we report the incidence of the contralateral psoas hematoma and its neurological sequelae following retroperitoneal transpsoas LLIF. There have previously been reports of contralateral neural injury with this procedure, ${ }^{11,13}$ but to our knowledge this is the first description of contralateral vascular injury after LLIF.

\section{Methods}

After obtaining institutional review board approval, we performed a multicenter retrospective review of all patients undergoing elective retroperitoneal transpsoas LLIF from 2008 to 2014. The institutions involved were the following: University of South Florida's Department of Neurosurgery (Tampa, Florida), Florida Orthopaedic Institute (Tampa, Florida), Duke University Medical Center (Durham, North Carolina), and Instituto de Patologia da Coluna (São Paulo, Brazil). The specific indications for surgery varied among institutions but included degenerative disc disease, spondylolisthesis, adult degenerative deformity, and spinal stenosis. Exclusion criteria included an underlying diagnosis of trauma or neoplasia because these could be potential confounders for the source of hemorrhage. All centers involved are considered to have expertise in the lateral approach, having experience with more than 1000 cases per center. Each of the senior authors has experienced this complication and is considered to be an expert in lateral access.
Constructs included both single-level and multilevel constructs with the majority supplemented with posterior percutaneous pedicle-screw fixation. Stand-alone constructs were included as well. Lateral corpectomies were excluded. Allograft was used in each of the interbody cages. All patients underwent standard preoperative imaging that included axial and sagittal MRI. The exact surgical technique varied among surgeons but was defined as a minimally invasive retroperitoneal transpsoas LLIF using neuromonitoring. In all cases, the contralateral annulus was released with an instrument of the surgeon's choosing, and an interbody cage was placed that spanned both lateral edges of the apophyseal ring. Complications and clinical outcomes were self-reported by each surgeon. The contralateral psoas hematoma was first diagnosed using a clinical examination and then confirmed with MRI. Clinical follow-up was at least 12 months.

\section{Results}

There were 3950 lumbar interbody cages placed via the lateral transpsoas approach, with 7 cases $(0.18 \%$ incidence) of symptomatic contralateral psoas hematoma, 3 of which required reoperation for hematoma evacuation. A summary of the clinical information for these 7 cases is provided in Table 1. Five of these patients were male. The mean age was 64 and mean BMI was 31. Two patients had been receiving chronic antiplatelet agents, which were stopped several days prior to their elective procedures. In 1 case,

TABLE 1. Clinical summary of patients developing contralateral psoas hematoma following lateral minimally invasive LLIF

\begin{tabular}{|c|c|c|c|c|c|c|c|c|c|c|}
\hline $\begin{array}{l}\text { Age } \\
\text { (yrs), } \\
\text { Sex }\end{array}$ & $\begin{array}{l}\mathrm{BMI} \\
\mathrm{kg} / \mathrm{m}^{2}\end{array}$ & Pathology & $\begin{array}{l}\text { Side of } \\
\text { Original } \\
\text { Approach }\end{array}$ & $\begin{array}{c}\text { Side of } \\
\text { Hematoma }\end{array}$ & Reop & $\begin{array}{l}\text { Days } \\
\text { Until } \\
\text { Reop }\end{array}$ & $\begin{array}{c}\text { Postop Adverse Event \& } \\
\text { Outcome }\end{array}$ & $\begin{array}{l}\text { Postop } \\
\text { Outcome }\end{array}$ & $\begin{array}{c}\text { Anti- } \\
\text { Coagulation }\end{array}$ & Comorbidities \\
\hline $65, M$ & 30.7 & ASD; LSS & $\mathrm{Lt}$ & Rt & No & NA & $\begin{array}{l}\text { Psoas fluid collection at } \\
\text { L4-5 }\end{array}$ & Intact & No & \\
\hline $54, \mathrm{~F}$ & 41.73 & Spondy & $\mathrm{Lt}$ & Rt & Yes & 37 & $\begin{array}{l}\text { Psoas hematoma present- } \\
\text { ing w/ proximal ip/q } \\
\text { weakness }(1 / 5)\end{array}$ & $\begin{array}{l}\text { Residual deficit } \\
\quad(\text { rt ip/q 1/5) }\end{array}$ & No & $\begin{array}{l}\text { Obesity, HTN, } \\
\text { HL }\end{array}$ \\
\hline $72, \mathrm{~F}$ & 25.6 & $\begin{array}{l}\text { Scoliosis; } \\
\text { spondy; } \\
\text { LSS }\end{array}$ & $\mathrm{Lt}$ & Rt & No & NA & $\begin{array}{l}\text { Rt } 6 \times 4 \mathrm{~cm} \text { psoas hema- } \\
\text { toma, asymptomatic }\end{array}$ & Intact & No & HTN \\
\hline $67, \mathrm{M}$ & 25.11 & DDD & $\mathrm{Lt}$ & Rt & No & NA & $\begin{array}{l}\text { Rt retroperitoneal hema- } \\
\text { toma }\end{array}$ & $\begin{array}{r}\text { Residual deficit } \\
\text { (It psoas 4/5) }\end{array}$ & $\begin{array}{l}\text { Yes; clopidogrel } \\
\text { stopped } 4 \\
\text { days before }\end{array}$ & $\begin{array}{l}\text { CAD, COPD, } \\
\text { HL, HTN, } \\
\text { osteoarthritis, } \\
\text { gout }\end{array}$ \\
\hline
\end{tabular}

$\mathrm{ASA}=$ aspirin (acetylsalicylic acid); $\mathrm{ASD}=$ adjacent-segment disease; $\mathrm{BMI}=$ body mass index; $\mathrm{CAD}=$ coronary artery disease , COPD = chronic obstructive pulmonary disease; $\mathrm{DDD}=$ degenerative disc disease; $\mathrm{DM}=$ diabetes mellitus; $\mathrm{HL}=$ hyperlipidemia; $\mathrm{HTN}=$ hypertension; ip/q = iliopsoas/quadriceps; LB = lower back; LSS = lumbar spinal stenosis; NA = not applicable; RLE = right lower extremity; spondy = spondylolisthesis. 
clopidogrel was restarted immediately postoperatively for a history of recent coronary artery bypass graft. The left side was the side of approach in 4 cases. In 1 case, segmental artery injury was confirmed at the time of surgery; in the others, segmental vessel injury was suspected, although those instances could not be confirmed. Neurological deficits persisted in 3 patients ( 2 of whom underwent reoperation) while the others remained neurologically intact.

\section{Illustrative Case}

A 54-year-old obese woman presenting with lower back pain and left-sided radiculopathy underwent a left-sided L4-5 LLIF with percutaneous pedicle-screw instrumentation and reduction of a Meyerding Grade I spondylolisthesis. Immediately postoperatively, her left-sided radiculopathy improved and she was discharged in a stable condition. However, she then gradually developed right leg symptoms that progressed to hip flexor and knee extensor weakness, which did not improve with oral steroids and gabapentin. Her postoperative course was marked by serial visits to the emergency department, as well as a 2-week postoperative office visit. In each of these visits, her contralateral symptomatology (right side) was downplayed because her leftsided symptoms (approach side) greatly improved. She was told that her right-sided pain was likely due to "positioning." On one occasion, she had experienced a ground-level fall at home due to progressive right-leg weakness, and was finally readmitted. Evaluation for persistent right leg pain and weakness prompted a CT scan, which demonstrated a right psoas mass. This was further evaluated using MRI (Fig. 1), which was interpreted as a psoas abscess versus an evolving hematoma.

Further review of the MRI demonstrated aberrant segmental vessel position adjacent to the L4-5 disc (Fig. 1). The patient was taken to surgery for hematoma evacuation, which was performed using the standard lateral retroperitoneal transpsoas approach contralateral to the side of the original approach. Segmental vessel injury was confirmed at the time of operation. She ultimately regained right hip flexion or knee extension but remained with residual weakness (strength 4/5) at 1-year follow up.

\section{Discussion}

The contralateral psoas hematoma is a unique complication that may often be overlooked. In our multicenter series, the presentation was nonspecific, but typically included dull pain on the contralateral side of access and may or may not have been associated with iliopsoas or femoral nerve weakness. Furthermore, the symptoms can have an insidious onset as in our case illustration and lead to a delay in diagnosis. Typically, contralateral pain and even minor weakness has been dismissed as a "pain limited weakness" or "it's just from positioning," and we tell both ourselves and our patients that "it should get better with time." This mentality was an error on our part, assuming that pathology on the contralateral side of access would be uncharacteristic. We hope that our experience will raise suspicion of this complication with the presence of any contralateral symptoms.

There were a total of 7 cases $(0.18 \%, 7 / 3950)$ of symp-

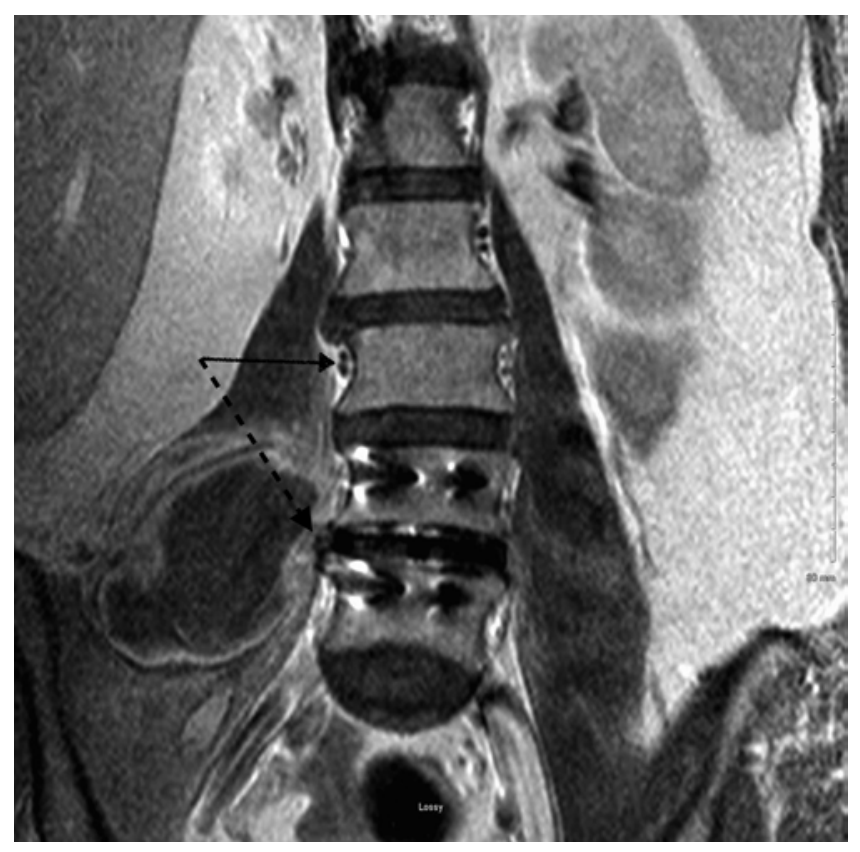

FIG. 1. Postcontrast coronal T1-weighted lumbar spine MR image demonstrating a right psoas hematoma. The dashed arrow indicates the aberrant segmental vessel, the solid arrow indicates normal segmental anatomy.

tomatic contralateral psoas hematoma in almost 4000 levels that underwent operations. Because postoperative MRI was not performed on every patient, the true radiographic incidence is not known. Three of the 7 cases resulted in postoperative deficit. One patient developed quadriceps and iliopsoas weakness (1/5) that did not recover despite reoperation; the others demonstrated only $4 / 5$ weakness (Table 1). Three of the 7 cases underwent reoperation, in which 2 showed no improvement and the other remained intact (operated on for severe anemia). Interestingly, all 3 reoperations occurred at almost 1 month after the initial operation. This delay is likely due to a combination of the naivety of the surgeon to the pathology, reinforced by the contralateral symptomology, and the insidious and nonspecific nature of presentation.

The use of antiplatelet therapy was noted in 2 cases. However, in each case, the antiplatelet therapy was stopped at least 4 days prior to surgery, and restarted 7 days after surgery in 1 instance and immediately after in the other. It is beyond the scope of this article (and difficult given the rarity of occurrence) to identify specific risk factors for contralateral hematoma formation, but we speculate that antiplatelet therapy could lead to an increased propensity of hemorrhage. The specific patient characteristics of each case can be found in Table 1 .

The exact mechanism of injury was not identified in each case, but we believe contralateral psoas hemorrhage resulted from segmental vessel injury during release of the contralateral annulus. This theory was confirmed in the illustrative case and remains suspected in the others. Bilateral segmental arteries arise from the aorta at each thoracic and lumbar spinal level and drift posteriorly at the midvertebral body level (Fig. 1) before entering the 
spinal canal through the intervertebral foramen..$^{15}$ These segmental arteries give rise to an extensive collateral network supplying the anterior spinal artery at the thoracic level and an extensive paraspinous network feeding the iliopsoas, erector spinae, and other associated muscles as well as the vertebral column and associated extradural structures. ${ }^{7,8,15}$

The maneuver of releasing the contralateral annulus is a routine step in performing minimally invasive LLIF. It allows for greater disc space distraction and permits implant placement to span across both lateral margins of the apophyseal ring, maximizing endplate support and indirect neural decompression. This maneuver is typically performed blindly but under fluoroscopic guidance using a Cobb elevator. In no cases was brisk arterial hemorrhage noted after this maneuver. A potential risk factor for vessel injury is "plunging" of the instrument past the lateral edge of the vertebral body while releasing the contralateral annulus. "Plunging" is easy to allow if the appropriate counterforce is not used while performing the maneuver. It takes a considerable amount of force to break through the contralateral annulus and, if unchecked, can result in contralateral damage. Despite identifying this complication, we continue to release the contralateral annulus because we believe it provides much greater value than risk to the procedure. However, we now have a much higher index of suspicion for contralateral symptoms.

A potential method for complication avoidance is identification of the segmental vessels on imaging as part of the routine preoperative evaluation-specifically, assessing coronal images to identify and visualize the vessels in relation to the disc space. ${ }^{9}$ We have added these sequences to the preoperative imaging studies in our practice and have had no further occurrences. If these vessels are identified, the surgeon may alter the side of approach to directly visualize the artery or choose a different technique for interbody fusion altogether.

\section{Conclusions}

The contralateral psoas hematoma is a rare but potentially devastating complication from the lateral transpsoas approach. Its symptoms are insidious and nonspecific, requiring the surgeon to maintain a high index of suspicion for diagnosis. Reoperation did not appear to benefit neurological outcome although it was performed in a delayed fashion. Preoperative screening with coronal T2-weighted imaging for aberrant segmental vessel anatomy may help avoid this complication by altering the surgical approach.

\section{References}

1. Aichmair A, Fantini GA, Garvin S, Beckman J, Girardi FP: Aortic perforation during lateral lumbar interbody fusion. J Spinal Disord Tech 28:71-75, 2015

2. Anand N, Baron EM: Urological injury as a complication of the transpsoas approach for discectomy and interbody fusion. J Neurosurg Spine 18:18-23, 2013

3. Assina R, Majmundar NJ, Herschman Y, Heary RF: First report of major vascular injury due to lateral transpsoas approach leading to fatality. J Neurosurg Spine 21:794-798, 2014
4. Brier-Jones JE, Palmer DK, Ĭnceoğlu S, Cheng WK: Vertebral body fractures after transpsoas interbody fusion procedures. Spine J 11:1068-1072, 2011

5. Dakwar E, Le TV, Baaj AA, Le AX, Smith WD, Akbarnia BA, et al: Abdominal wall paresis as a complication of minimally invasive lateral transpsoas interbody fusion. Neurosurg Focus 31(4):E18, 2011

6. Dakwar E, Rifkin SI, Volcan IJ, Goodrich JA, Uribe JS: Rhabdomyolysis and acute renal failure following minimally invasive spine surgery: report of 5 cases. J Neurosurg Spine 14:785-788, 2011

7. Etz CD, Kari FA, Mueller CS, Brenner RM, Lin HM, Griepp RB: The collateral network concept: remodeling of the arterial collateral network after experimental segmental artery sacrifice. J Thorac Cardiovasc Surg 141:1029-1036, 2011

8. Etz CD, Kari FA, Mueller CS, Silovitz D, Brenner RM, Lin HM, et al: The collateral network concept: a reassessment of the anatomy of spinal cord perfusion. J Thorac Cardiovasc Surg 141:1020-1028, 2011

9. Hu WK, He SS, Zhang SC, Liu YB, Li M, Hou TS, et al: An MRI study of psoas major and abdominal large vessels with respect to the X/DLIF approach. Eur Spine J 20:557-562, 2011

10. Le TV, Smith DA, Greenberg MS, Dakwar E, Baaj AA, Uribe JS: Complications of lateral plating in the minimally invasive lateral transpsoas approach. J Neurosurg Spine 16:302-307, 2012

11. Papanastassiou ID, Eleraky M, Vrionis FD: Contralateral femoral nerve compression: An unrecognized complication after extreme lateral interbody fusion (XLIF). J Clin Neurosci 18:149-151, 2011

12. Santillan A, Patsalides A, Gobin YP: Endovascular embolization of iatrogenic lumbar artery pseudoaneurysm following extreme lateral interbody fusion (XLIF). Vasc Endovascular Surg 44:601-603, 2010

13. Sofianos DA, Briseño MR, Abrams J, Patel AA: Complications of the lateral transpsoas approach for lumbar interbody arthrodesis: a case series and literature review. Clin Orthop Relat Res 470:1621-1632, 2012

14. Tormenti MJ, Maserati MB, Bonfield CM, Okonkwo DO, Kanter AS: Complications and radiographic correction in adult scoliosis following combined transpsoas extreme lateral interbody fusion and posterior pedicle screw instrumentation. Neurosurg Focus 28(3):E7, 2010

15. Tsirikos AI, Howitt SP, McMaster MJ: Segmental vessel ligation in patients undergoing surgery for anterior spinal deformity. J Bone Joint Surg Br 90:474-479, 2008

\section{Disclosures}

Dr. Billys has served as a consultant to Medtronic, NuVasive, St. Jude Medical, Alphatec, and Centinel Spine, and is a patent holder for NuVasive. Dr. Isaacs has served as a consultant to NuVasive; has received grants, contracts, or royalties from $\mathrm{NuVasive}$; has received travel reimbursement from the Association for Collaborative Spine Research; and has acted as a scientific advisor to Providence Medical Technology. Dr. Pimenta has served as a consultant to, has direct stock ownership in, and is a patent holder for NuVasive. Dr. Uribe has served as a consultant to $\mathrm{NuVasive.}$

\section{Author Contributions}

Conception and design: Uribe. Acquisition of data: Uribe, Park, Billys, Isaacs, Pimenta. Analysis and interpretation of data: Park, Isaacs, Pimenta. Drafting the article: Beckman, Vincent, Park. Critically revising the article: Uribe, Beckman, Vincent, Park, Pimenta. Reviewed submitted version of manuscript: Uribe, 
Beckman, Park. Approved the final version of the manuscript on behalf of all authors: Uribe. Administrative/technical/material support: Billys, Isaacs, Pimenta. Study supervision: Uribe, Pimenta.

\section{Supplemental Information}

Previous Presentations

Portions of this work were presented in poster form at the 2014
Annual CNS Meeting, in Boston, Massachusetts, October 18-22, 2014, and the 4th Annual World Congress of Minimally Invasive Spine Surgery and Techniques, Paris, France, June 11-14, 2014.

\section{Correspondence}

Juan S. Uribe, Department of Neurosurgery \& Brain Repair, Morsani College of Medicine, University of South Florida, 2 Tampa General Cir., 7th Fl., Tampa, FL 33606. email: jsuribe@ gmail.com. 